J. Clin. Chem. Clin. Biochem.

Vol. 25, 1987, pp. 689-698

(C) 1987 Walter de Gruyter \& Co.

Berlin - New York

\title{
Festphasen-Radioimmunoassay zur quantitativen Bestimmung von antigenspezifischen IgG-Antikörpern im Serum von Patienten mit Farmerlunge ${ }^{1}$ )
}

\author{
Von W. Weiss und X. Baur \\ Pneumologische Abteilung, Medizinische Klinik I, Klinikum Großhadern, Universität München
}

(Eingegangen am 13. Mai/7. Juli 1987)

\begin{abstract}
Zusammenfassung: In der vorliegenden Arbeit wird über die Entwicklung eines sensitiven FestphasenRadioimmunoassays (Mikrotiterplatten-RIA) zur quantitativen Bestimmung von antigenspezifischen IgGAntikörpern bei Patienten mit Farmerlunge berichtet. Die Beschichtung der Mikrotiterplatten erfolgte mit Antigenen aus Aspergillus fumigatus, Micropolyspora faeni, Aureobasidium pullulans, Alternaria tenuis, Thermoactinomyces vulgaris und Heu. Wir ermittelten die Kinetik der Antikörper- und Protein A-Bindung, die Temperaturabhängigkeit des Assays sowie die optimale Antigenkonzentration und Serumverdünnung. Ein Vergleich zwischen mit Glutaraldehyd aktivierten und nicht aktivierten Mikrotiterplatten ergab, daß die Glutaraldehydaktivierung eine Zunahme der detektierbaren Antikörper auf etwa das 10 fache bewirkt; allerdings ändert sich durch diese Maßnahme das Verhältnis der Werte von Patienten und von Kontrollpersonen nur unwesentlich.
\end{abstract}

Solid-phase radioimmunoassay for the quantitative determination of antigen-specific IgG in sera of patients suffering from farmer's lung

Summary: In this study we have investigated a number of technical aspects of a sensitive solid-phase radioimmunoassay (microtitre-plate RIA) for the quantitative determination of antigen-specific IgG antibodies in the sera of patients suffering from farmer's lung. Microtitre-plates were coated with antigens of Aspergillus fumigatus, Micropolyspora faeni, Aureobasidium pullulans, Alternaria tenuis, Thermoactinomyces vulgaris and hay. Optimal antigen concentration and serum dilution were determined, the temperaturedependence of the assay and the kinetics of the binding of antibodies and protein A were studied. A comparison between glutaraldehyde-activated and non-activated microtitre-plates showed that the RIA with activated microtitre-plates produces values approximately 10-times higher than those with non-activated plates. However, the use of activated plates did not significantly increase the ratio between patient and control values.

\section{Einfüibrung}

Die Farmerlunge ist eine in regenreichen Gebieten (u. a. Nordseeküste, Voralpenland) vorkommende, zu den exogen-allergischen Alveolitiden (vorwiegend

\footnotetext{
1) Mit Unterstützung durch die Deutsche Forschụngsgemeinschaft
}

Typ III-Allergie) zählende Erkrankung, die durch das Einatmen von schimmeligem Heustaub verursacht wird. Als ursächliche Antigene wurden Sporen- und Zellbestandteile von Schimmelpilzen und thermophilen Actinomyceten identifiziert. Dem Nachweis von Antikörpern gegen Komponenten dieser Mikroorganismen kommt als Routine- und Screeningmethode für die Diagnosestellung besondere Bedeutung zu (1). 
Zur quantitativen Bestimmung derartiger allergenund antigenspezifischer Immunglobuline finden heute in zunehmendem Maße radio- und enzymimmunologische Untersuchungsverfahren Verwendung, insbesondere nichtkompetitive Festphasen-Immunoassays.

Während Radioimmunoassays zum Nachweis von IgE-Antikörpern schon seit etwa 20 Jahren im Einsatz sind (2), gab es bei der Entwicklung entsprechender Immunoassays zur Bestimmung von IgG-Antikörpern gegen Inhalationsallergene lange Zeit technische Schwierigkeiten, die vor allem mit dem Phänomen einer hohen „Backgroundaktivität" zusammenhingen und auf eine unspezifische Bindung von Antikörpern an die Festphase oder das Auftreten von Immunkomplexen zurückgeführt werden.

1984 berichteten wir über die Entwicklung eines Radioimmunoassays, bei dem wir als feste Phase mit Antigenen beschichtete Cellulosescheiben und zur Detektion gebundener IgG-Antikörper ${ }^{125}$ I-markiertes Protein A benutzten (3). Protein A ist ein Protein aus der Zellwand von Staphylococcus aureus, welches sich hauptsächlich an die IgG-Subtypen 1, 2 und 4 bindet (4). Dieser Papierscheiben-RIA erwies sich anderen Methoden wie z. B. der Doppelimmunodiffusionsmethode nach Ouchterlony (5) hinsichtlich Empfindlichkeit und Spezifität als deutlich überlegen (6). Allerdings beobachteten wir bei etwa $30 \%$ der untersuchten Seren von Patienten mit exogen-allergischer Alveolitis (Farmerlunge, Vogelhalterlunge) eine Bindung an die Cellulosescheiben, welche durch zugesetztes freies Antigen nicht inhibierbar war und von uns auf Cellulose-bindende Antikörper in diesen Seren zurückgeführt wird (7).

Zur Beseitigung dieser Schwierigkeiten entwickelten wir nun einen Radioimmunoassay, der mit an die Plastikoberfläche einer Mikrotiterplatte gebundenen Antigenen arbeitet. Wir führten hierbei unter Verwendung von Antigen-Extrakten aus Aspergillus fumigatus, Micropolyspora faeni, Alternaria tenuis, Aureobasidium pullulans, Thermoactinomyces vulgaris und Heu folgende Untersuchungen durch:

Vergleich zwischen mit Glutaraldehyd aktivierten und nicht aktivierten Microtiterplatten,

Bestimmung der optimalen Antigenkonzentration und der optimalen Serumverdünnung,

Erfassung der Bindungskinetik von Antikörpern und Protein A und des Einflusses der Temperatur auf den Assay.

Außerdem wurde die Verteilung der Antikörperwerte in einem Kontrollkollektiv $(n=38)$ dargestellt und schließlich der Mikrotiterplatten-RIA mit dem herkömmlichen Papierscheiben-RIA bei Patienten mit IgG-Antikörpern gegen Cellulose verglichen.

\section{Material und Methoden}

Mikrotiterplatten mit herausnehmbaren Einsätzen (removablewell ${ }^{\circledR}$ ) wurden von Dynatech (Denkendorf, FRG), Glutardialdehyd, Tween 20 und Reagenzien für Puffer von Merck (Darmstadt, FRG), Rinderserumalbumin ( $\gamma$-Globulin-frei) von Sigma (München, FRG) und ${ }^{125}$ I-markiertes Protein $A$ von NEN (Dreieich, FRG) bezogen.

Antigene żur Beschichtung der Mikrơtiterplatten (Antigene von Aspergillus fumigatus, Micropolyspora faeni, Aureobasidium pullulans, Alternaria tenuis, Thermoactinomyces vulgaris und $\mathrm{Heu}$ stammten von HAL (Groningen, NL; Precipitha1@). Der Inhalt eines jeden Fläschchens wurde in $2 \mathrm{ml}$ dest. Wasser gelöst, portioniert und bei $-20^{\circ} \mathrm{C}$ bis zum Verbrauch gelagert. Den Proteingehalt der auf diese Weise erhaltenen Antigenlösungen bestimmten wir mit der Methode nach Lowry (8), wobei Rinderserumalbumin als Referenz verwendet wurde.

\section{Pufferlösungen}

Als Kopplungșpuffer diente Carbonatpuffer $(0,05 \mathrm{~mol} / \mathrm{l}$ $\mathrm{NaHCO} / \mathrm{Na}_{2} \mathrm{CO}_{3}, \mathrm{pH} 9,3$ ), als Assay-Puffer Na-Phosphatpuffer (PBST) $\left(0,05 \mathrm{~mol} / 1 \quad \mathrm{Na}_{2} \mathrm{HPO}_{4} / \mathrm{NaH}_{2} \mathrm{PO}_{4} ; 9 \mathrm{~g} / 1 \mathrm{NaCl} ; 1 \mathrm{~g} / 1\right.$ Tween 20; $1 \mathrm{~g} / 1$ Rinderserumalbumin; $0,2 \mathrm{~g} / 1 \mathrm{NaN}_{3}, \mathrm{pH} 7,5$ ).

\section{Patienten- und Kontrollseren}

Wir verwendeten für die folgenden Versuche Seren von 25 Personen mit gesicherter Farmerlunge, die präzipitierende Antikörper gegen obige Antigene aufwiesen, ferner von 38 gesunden Kontrollpersonen (Klinikpersonal, freiwillige Blutspender); Einzelheiten zu den klinischen Untersuchungen siehe Baur et al. (9). Alle Seren wurden portioniert und bei $-20^{\circ} \mathrm{C}$ gelagert.

\section{Mikrotiterplatten-RIA}

Mit Antigen beschichtete Mikrotiterplatten werden mit verdünntem Humanserum inkubiert und nicht gebundéne Antikörper durch anschließendes Waschen mit Assay-Puffer entfernt. Dann erfolgt die Inkubation der Mikrotiterplatten mit radioaktiv markiertem Protein $\mathrm{A}$, welches sich an die spezifisch gebundenen IgG-Antikörper anlagert. Nach erneutem Waschen mit Assay-Puffer wird die gebundene Radioaktivität gemessen, wo= bei die Anzahl der gemessenen Zerfälle pro Minute proportional der Antikörperkonzentration ist.

Wie Vorversuche ergaben, beträgt die Haltbarkeit beschichteter Mikrotiterplatten bei $-20^{\circ} \mathrm{C}$ im luftdicht verpackten Zustand mindestens 3 Monate.

Im einzelnen führten wir folgende Arbeitsschritte durch: Zum Aktivieren der Mikrotiterplatten mit Glutaraldehyd pipettierten wir pro Vertiefung $100 \mu$ l Glutardialdehyd $(10 \mathrm{~g} / \mathrm{l}$ in Kopplungspuffer) ein. Nach $1 \mathrm{~h}$ bei $15-20^{\circ} \mathrm{C}$ wurde die Lösung abgesaugt und die Mikrotiterplatten wurden zweimal mit je $250 \mu \mathrm{l}$ Kopplungspuffer gewaschen. Die Beschichtung der Mikrotiterplatten erfolgte mit $100 \mu$ antigenhaltigem Kopplungspuffer. Im Anschluß an die Inkubation über Nacht bei $15-20^{\circ} \mathrm{C}$ wurde am darauf folgenden Tag die Lösung aus den Mikrotiterplatten abgesaugt, zweimal mit je $250 \mu$ Assay-Puffer gewaschen und anschließend eventuell noch unbesetzte Bindungstellen der Mikrotiterplatten durch Zugabe von $250 \mu l$ Assay-Puffer ( $1 \mathrm{~h}$ Inkubation bei Raumtemperatur) abgesättigt. Nach einem weiteren Waschvorgang gaben wir pro Vertiefung je $100 \mu \mathrm{l}$ Serum (verdünnt in Assay-Puffer) zu (Doppelbestimmungen) und ließen die Proben bei $4^{\circ} \mathrm{C}$ über Nacht stehen. Am nächsten Tag erfolgte nach viermaligem Waschen mit je $250 \mu \mathrm{l}$ Assay-Puffer die Detektion des gebundenen IgG durch $\therefore$

J. Clin. Chem. Clin. Biochem. / Vol. 25, 1987 / No. 10 
Zugabe von radioaktiv markiertem Protein A. Dazu wurden $100 \mu l$ in Assay-Puffer verdünnter ${ }^{125}$-Protein A-Lösung (je Vertiefung etwa $100000 \mathrm{Impulse} / \mathrm{min}$ ) hinzugefügt, nach $2 \mathrm{~h}$ bei Raumtempcratur abgesaugt und viermal mit je $250 \mu$ l AssayPuffer gewaschen. Anschlicßend nahmen wir dic Plastikeinsätze aus den Halterungen heraus und bestimmten die gebundene Radioaktivität im Gamma-Counter.

Die Ergebnissc sind als Impulsc pro Minutc angegeben.

\section{Ergebnisse}

\section{Einfluß der Glutaraldehydaktivierung}

Den Einfluß der Glutaraldehydaktivierung auf den Mikrotiterplatten-RIA untersuchten wir am Beispiel der Aspergillus fumigatus-Antigene (siehe Abb. $1 \mathrm{a}-$ $1 \mathrm{~d})$.

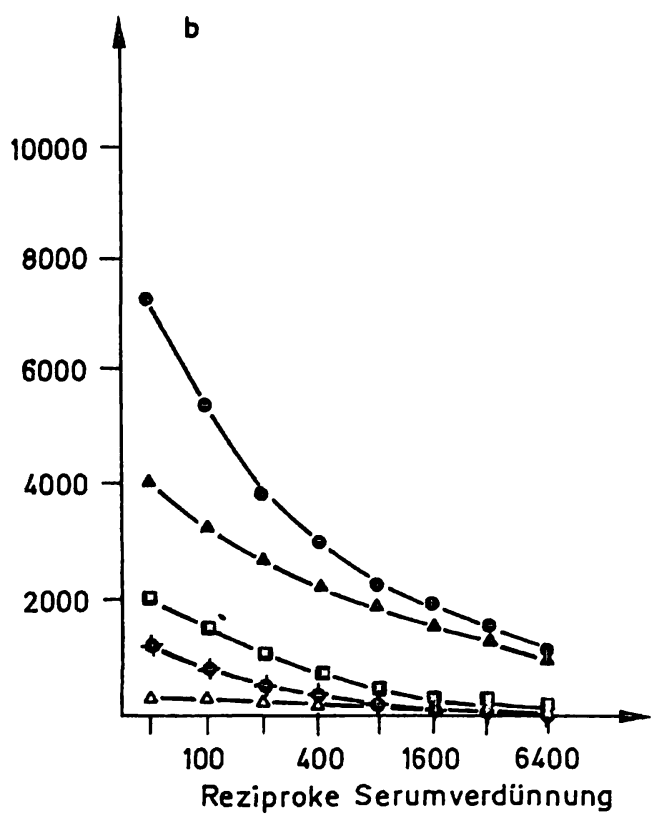

b) Mikrotiterplatte nicht mit Glutaraldehyd aktiviert Serummenge, Serumverdünnung und Antigenmenge wie bei Abb. 1 a

\section{Serummenge: $100 \mu \mathrm{l}$; Serumverdünnung 1:50-1:6400 Antigenmenge: $100 \mu$ l (Proteinkonzentration: $50 \mathrm{mg} / \mathrm{l}$ )}

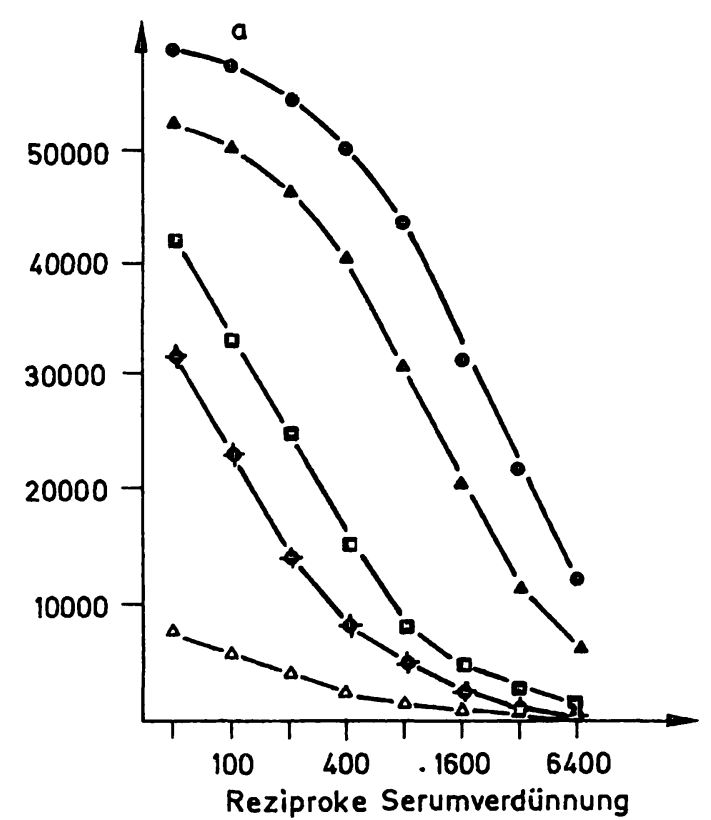

政

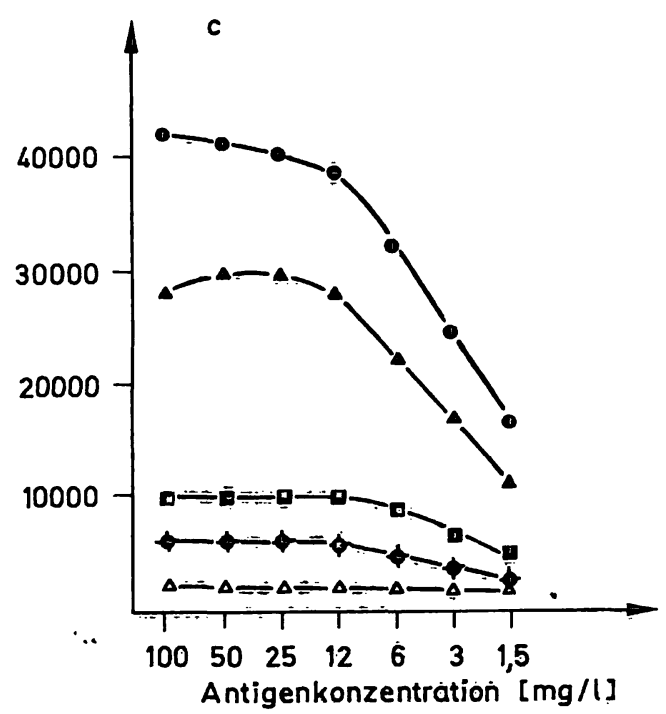

c) Mikrotiterplatte mit Glutaraldehyd aktiviert Serummenge: $100 \mu \mathrm{l}$; Serumverdünnung 1:500 Antigenmenge: $100 \mu \mathrm{l}$; (Proteinkonzentration: $100 \mathrm{mg} / 1-1,5 \mathrm{mg} / \mathrm{l}$ )

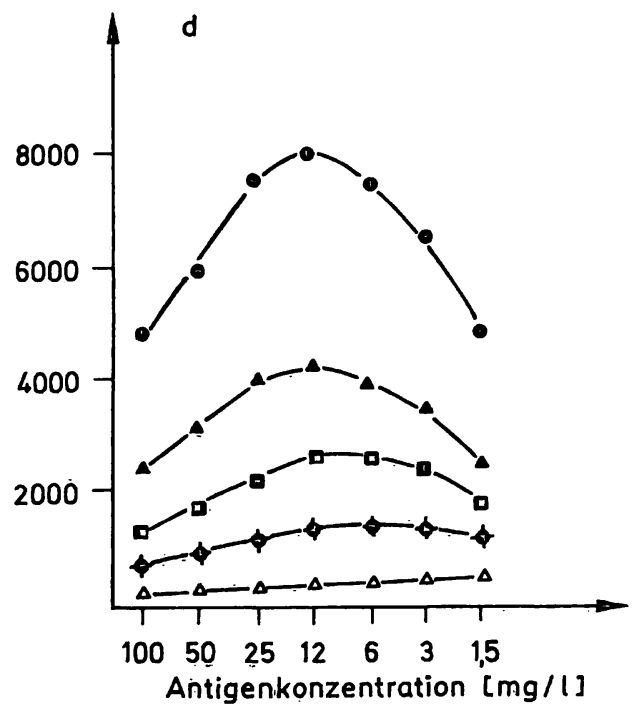

d) Mikrotiterplatte nicht mit Glutaraldehyd aktiviert Serummenge: $100 \mu \mathrm{l}$; Serumverdünnung 1:50 Antigenmenge: $100 \mu \mathrm{l}$; (Proteinkonzentration: $100 \mathrm{mg} / \mathrm{l}-1,5 \mathrm{mg} / \mathrm{l}$ )

Abb. 1. Einfluß der Glutaraldehydaktivierung auf den Mikrotiterplatten-RIA (Aspergillus fumigatus-Antigene)

Patientenserum = geschlossene Symbole; Kontrollserum $=$ offene Symbole 
Folgende Resultate wurden erzielt:

a) Bei konstanter Antigenkonzentration $(50 \mathrm{mg} / \mathrm{l})$ ergibt sich für eine bestimmte Serumverdünnung bei mit Glutaraldehyd aktivierten Mikrotiterplatten ein jeweils 10-20fach höherer Wert (Impulse/ $\min$ ) als bei Verwendung nicht aktivierter Mikrotiterplatten (siehe Abb. 1a-1 b). Allerdings liegen nicht nur die Werte der Patienten, sondern auch diejenigen der Kontrollpersonen um diesen Faktor höher, so daß das Verhältnis von Patienten- und Kontrollpersonenwerten mit und ohne Glutaraldehydaktivierung in etwa gleich ist. Wegen der ohne Aktivierung niedrigen Werte der Kontrollpersonen (200-300 Impulse/min) bei einem unspezifischen „Background“ von 30-60 Impulsen/ min ist eine relativ lange Meßzeit (etwa $5 \mathrm{~min}$ ) erforderlich; werden dagegen mit Glutaraldehyd aktivierte Mikrotiterplatten verwendet, reicht eine Zählzeit von $1 \mathrm{~min}$ aus.

b) Bei konstanter Serumverdünnung und zunehmender Antigenkonzentration erbält man im Falle der mit Glutaraldehyd aktivierten Mikrotiterplatten mit zunehmender Antigenkonzentration zunächst einen linearen Anstieg der Antikörperbindung, der dann in ein Plateau einmündet (Sättigungskurve siehe Abb. 1c).

Hingegen weist die entsprechende Kurve der nicht aktivierten Mikrotiterplatten ein relativ enges $\mathrm{Ma}$ ximum bei Antigenkonzentrationen von $10 \mathrm{mg} / \mathrm{l}$ auf, welches nach beiden Seiten hin rasch abfällt (siehe Abb. 1d).

Für die weiteren Untersuchungen setzten wir ausschließlich mit Glutaraldehyd aktivierte Mikrotiterplatten ein (Gründe hierfür siehe unter Diskussion).

Ermittlung der optimalen Serumverdünnung

Patienten- und Kontrollseren wurden in $\log _{2}$-Schritten verdünnt $(1: 50-1: 6400)$ und die optimale Serumverdünnung ermittelt, bei welcher der Quotient aus Patienten- und Kontrollpersonenwerten möglichst groß wird, d.h. der Unterschied zwischen beiden Gruppen maximal wird. Es stellte sich heraus, $\mathrm{da} ß$ die optimale Serumverdünnung für verschiedene Antigene zwar geringfügig schwankt, sich aber stets im Bereich von 1:200-1:800 bewegt (siehe Abb. 2).

Für die Routinediagnostik wurde als Kompromiß eine einheitliche Serumverdünnung von 1:500 gewählt.
Ermittlung der optimalen Antigenkonzentration

Die für die Beschichtung der Mikrotiterplatten erforderliche optimale Proteinkonzentration der verschiedenen Antigenextrakte schwankte zwischen 5 und 100 $\mathrm{mg} / 1$ (siehe Abb. 3). Für die praktișche Anwendung erwies sich die in Tabelle 1 an'gegebene Proteinkonzentration als günstig. Näherungweise gilt: 1 Fläschchen Precipithal ${ }^{\circledR}$ in $2 \mathrm{ml} \mathrm{H}_{2} \mathrm{O}$ gelöst ist ausreichend für die Beschichtung von etwa 20 Mikrotiterplatten mit je 96 Vertiefungen.

Kinetik der Bindung von Antikörpern und Protein A

Der Einfluß der Inkubationsdauer auf das Ausmaß der Bindung von IgG-Antikörpern und Protein A wurde an mit Aspergillus fumigatus-Antigenen beschichteten Mikrotiterplatten untersucht.

\section{Kinetik der Antikörperbindung}

Wir inkubierten Mikrotiterplatten unterschiedlich lange $(0-24 \mathrm{~h})$ mit $1: 500$ verdünnten Patienten- und Kontrollseren. Die Inkubationșdauer mit Protein A betrug einheitlich $2 \mathrm{~h}$. Wie Abbildung $4 \mathrm{a}$ zeigt, erlaubt eine Inkubationsdauer von etwa $6 \mathrm{~h}$ die beste Differenzierung zwischen Kranken und Kontrollpersonen.

\section{Kinetik der Protein A-Bindung.}

Die Inkubation der Mikrotiterplatten mit Humanserum erfolgte über Nacht. Die Inkubationsdauer mit Protein A variierten wir von $0-5 \mathrm{~h}$. Wie Abbildung $4 \mathrm{~b}$ wiedergibt, wird in Abhängigkeit von der Antikörperkonzentration der verwendeten Seren nach 0,5$3 \mathrm{~h}$ ein Plateau erreicht.

Aus arbeitstechnischen Gründen führten wir in den weiteren Versuchen die Inkubation mit Serum über Nacht und die Inkubation mit Protein A über einen Zeitraum von $2 \mathrm{~h}$ durch.

Einfluß der Temperatur auf Antigen - und Antikörperbindung

Der Einfluß der Temperatur sowohl auf die Bindung der Antigene an die Mikrotiterplatten als auch auf die Bindung der IgG-Antikörper àn diese Antigene wurde an Antigenen von Aspergillus fumigatus; Alternaria tenuis und Aureobasidium pullulans genauer studiert, wobei folgende Kombinationen zur Anwendung kamen: Binden der Antigene an die $\therefore$

J. Clin. Chem. Clin. Biochem. / Vol. 25, 1987 / No. 10 

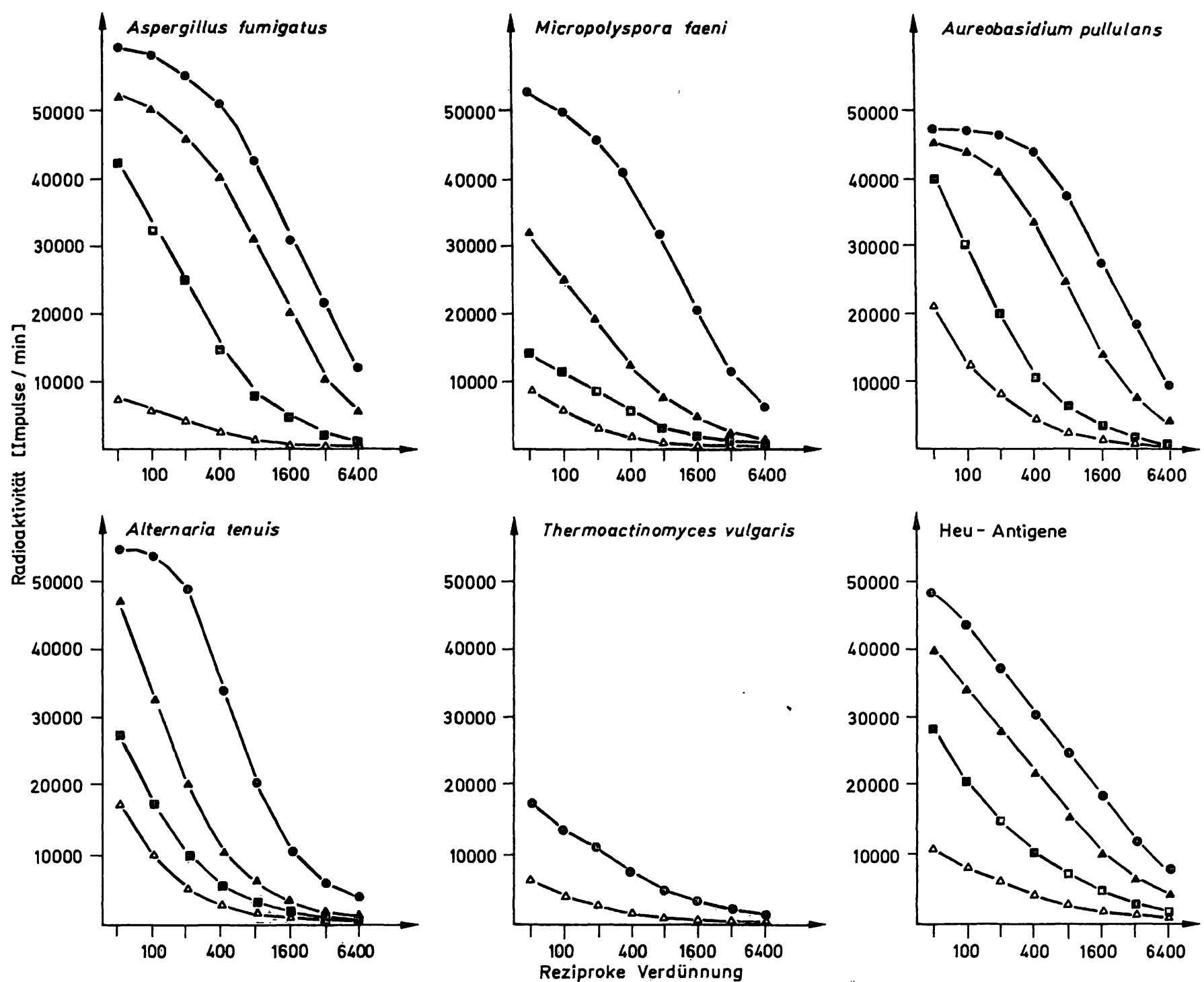

Abb. 2. Ermittlung der optimalen Serumverdünnung

Abszisse: Serumverdünnung: $1: 50-1: 6400$

Antigenkonzentration: einheitlich $50 \mathrm{mg} / \mathrm{l}$

Patientenserum = geschlossene Symbole; Kontrollserum = offene Symbole

Mikrotiterplatten bei $4^{\circ} \mathrm{C}$ und Seruminkubation bei $4^{\circ} \mathrm{C}$ bzw. $20^{\circ} \mathrm{C}$ sowwie Binden der Antigene an die Mikrotiterplatten bei $20^{\circ} \mathrm{C}$ und Inkubation mit Serum bei $4{ }^{\circ} \mathrm{C}$ bzw. $20^{\circ} \mathrm{C}$.

Generell ergibt șich, dạ bei höherer Temperatur 20$80 \%$ mehr Antigen gebunden wird (Ergebnisse nicht dargestellt) und dả eine Temperatur von $20^{\circ} \mathrm{C}$ beim Beschichten der Mikrotiterplatten und von $4^{\circ} \mathrm{C}$ bei der Inkubation mit Serum und Verwendung von Aspergillus funigatus-Antigenen die beste Differenzierung zwischen Kranken und Gesunden gestattet (Quotient aus den Werten für Kranke und denen für Gesunde ist besonders groß). Für andere Antigene ist diese Tendenz nicht so ausgeprägt nachweisbar (siehe Abb. 5).

\section{Untersuchung des Kontrollkollektivs}

Die IgG-Antikörperwerte von 38 Kontrollpersonen gegen 6 verschiedene Antigene (s. o.) sowie gegen nur mit Rinderserumalbumin beschichtete Mikrotiterplatten wurden bestimmt. Trägt man die Häufigkeit, mit der jeder der erhaltenen Werte in der Versuchsreihe auftritt, gegen das jeweilige Meßintervall auf, so erhält man in etwa eine Normalverteilung (siehe Abb. 6). Außerdem entsprechen jeweils $2 \bar{x}$ etwa $\overline{\mathbf{x}}+2 \mathrm{~s}, \mathrm{~d}$. h. der doppelte Mittelwert $(2 \overline{\mathrm{x}})$ des Kontrollkollektivs schließt etwa $95 \%$ der Kontrollpersonen ein. Für die Routinediagnostik wurden diese $2 \bar{x}$ Werte als Positiv-Negativ-Grenze festgelegt und als 1 Unit $(U)$ bezeichnet. Seren mit Werten $>2 \bar{x}$ stuften wir als positiv ein. 

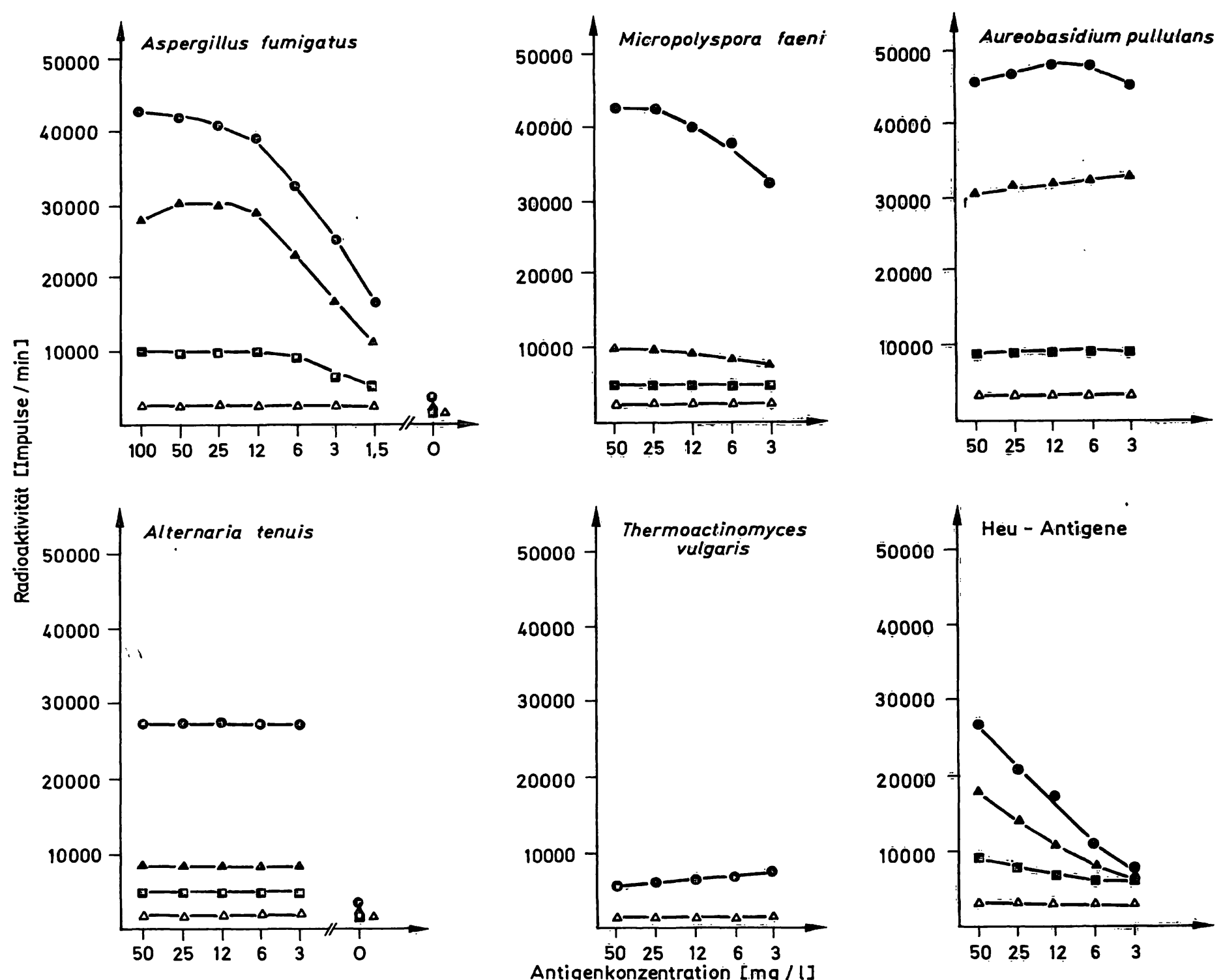

Abb. 3. Ermittlung der optimalen Antigenkonzentration

Abszisse: Serumverdünnung: einheitlich 1:500

Antigenkonzentration: $50 \mathrm{mg} / \mathrm{l}-3 \mathrm{mg} / \mathrm{l}$

Patientenserum = geschlossene Symbole; Kontrollserum = offenè Symbole

Tab. 1. Optimale Antigenkonzentration.

Proteingehalt des kommerziellen Antigenextrakts $(g / l)$
Empfohlene Proteinkonzentration zum Beschichten der Mikrotiterplatten $(\mathrm{mg} / \mathrm{l})$

$\begin{array}{llrc}\text { Aspergillus fumigatus } & 5 & 25-50 & 20-40 \\ \text { Micropolyspora faeni } & 7 & 25-50 & 30-50 \\ \text { Aureobasidium pullulans } & 1 & 5-25 & 10-40 \\ \text { Thermoactinomyces vulgaris } & 7 & 10-25 & 50 \\ \text { Alternaria tenuis } & 3 & 10-25 & 20-50 \\ \text { Heu } & 7 & 100 & 15\end{array}$

Anzahl der Beschichtungen (Mikrotiterplatten) pro Fläschchen kommerziellẹr Antigenlösung

.



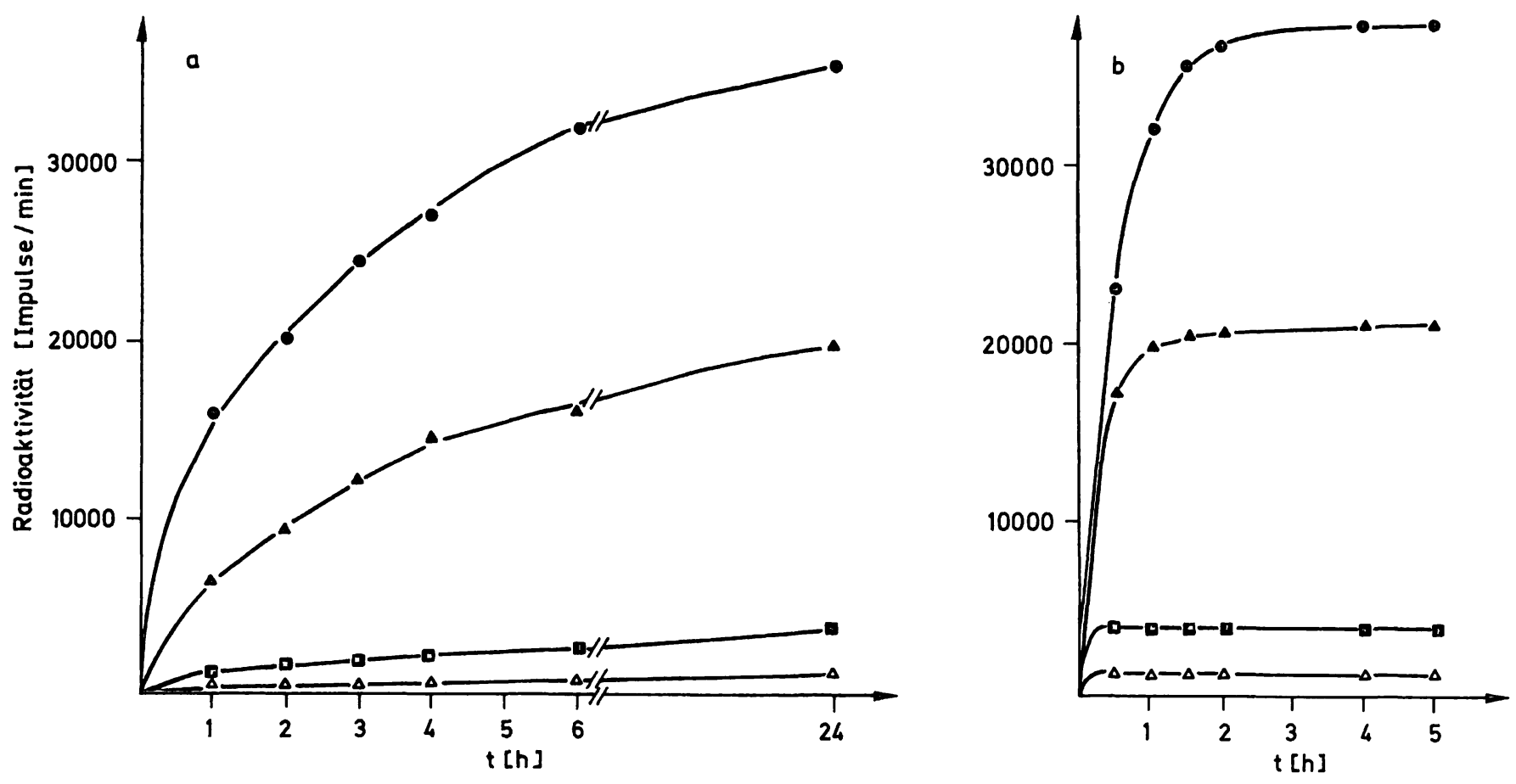

Abb. 4. a) Kinetik der Antikörperbindung an die Mikrotiterplatten:

Spezifische Antikörperbindung an mit Aspergillus fumigatus-Antigenen beschichtete Mikrotiterplatten. Die Inkubationszeit mit Humanserum wurde von $0-24 \mathrm{~h}$ variiert, die Inkubationszeit mit ${ }^{125}$ I-Protein A betrug jeweils $2 \mathrm{~h}$.

b) Kinetik der Bindung von ${ }^{125}$-I-Protein A an mit Aspergillus fumigatus-Antigenen beschichtete Mikrotiterplatten nach Inkubation mit Humanserum:

Die Inkubationsdauer mit Serum betrug konstant $18 \mathrm{~h}$, die Inkubationszeit mit ${ }^{125}$ I-Protein A wurde von $0-5 \mathrm{~h}$ variiert. Patientenserum $=$ geschlossene Symbole; Kontrollserum $=$ offene Symbole
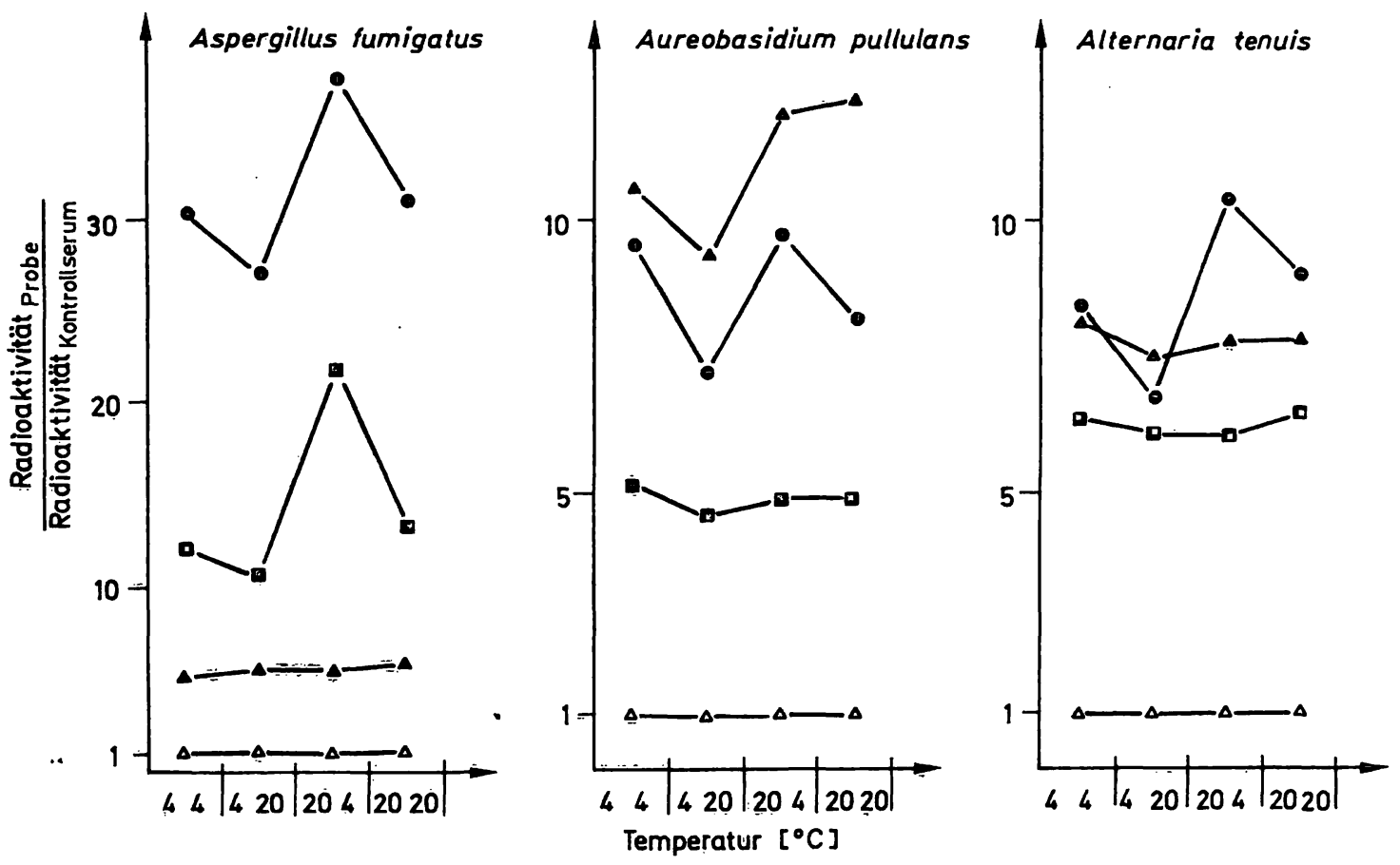

Abb. 5. Einfluß der Temperatur auf Antigen- und Antikörperbindung Linke Żahl: Temperatur bei der Beschichtung der Mikrotiterplatten rechte Zahl: Temperatur bei der Inkubation mit Serum

Patientenserum = gescblossene Symbole; Kontrollserum = offene Symbole 

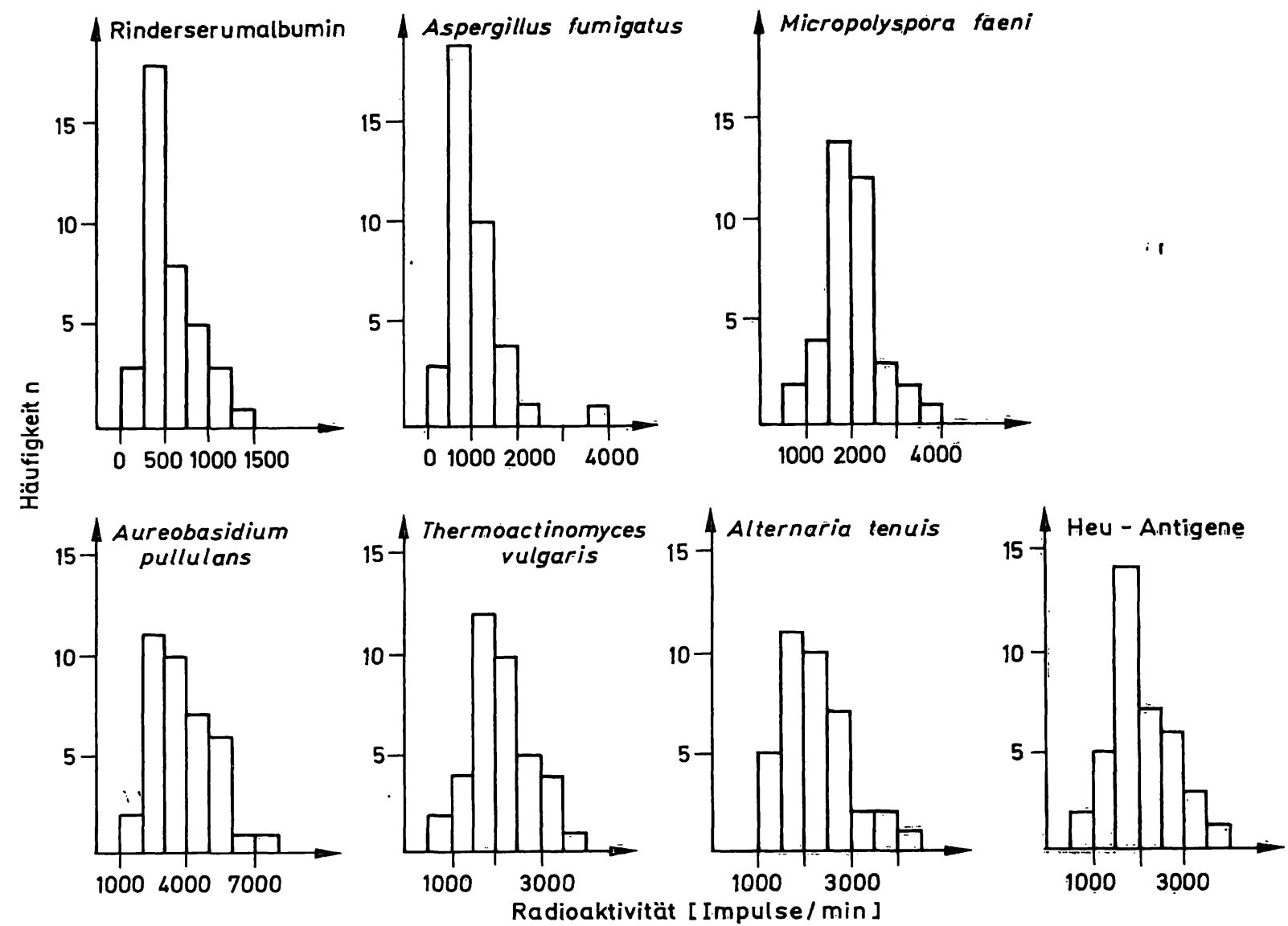

Abb. 6. Verteilung der Antikörperwerte innerhalb des Kontrollkollektivs
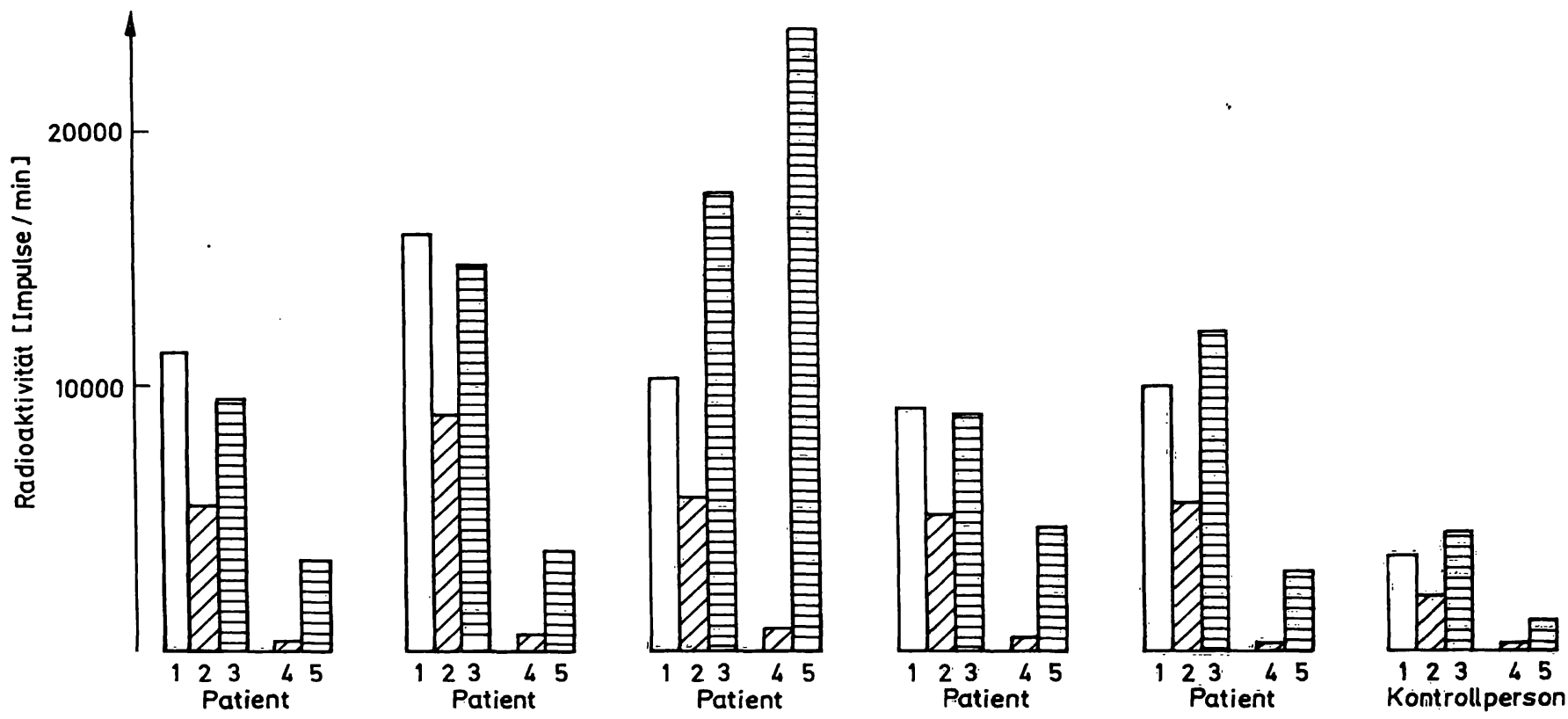

Abb. 7. Vergleich zwischen Papierscheiben- und Mikrotiterplatten-RIA bei 5 Patienten mit an Cellulose biṇdeñden IgG-Antikörpern:

$1=$ Cellulosescheiben, nicht mit Antigenen beschichtet

2 = Cellulosescheibe mit Rinderserumalbumin abgesättigt

2 = Cellulosescheibe mit Micropolyspora faeni-Antigenen beschichtet

4 = Mikrotiterplatte mit Rinderserumalbumin abgesättigt

5 = Mikrotiterplatte mit Micropolyspora faeni-Antigeneñ beschichtet

J. Clin. Chem. Clin. Biochem. / Vol. 25, 1987 / No. 10 
Patienten mit Cellulose-bindenden IgGAntikörpern

Patientenseren, die nach früheren Bestimmungen Cellulose-bindende IgG-Antikörper enthalten, wurden mittels des Mikrotiterplatten-RIA untersucht; die Ergebnisse verglichen wir mit denen des PapierscheibenRIA. Es zeigt sich, daß diese Patienten zwar im Vergleich zu Kontrollpersonen etwa doppelt so hohe Antikörperwerte bei Verwendung der mit Rinderserumalbumin beschichteten Mikrotiterplatten aufweisen, andererseits die hierbei erhaltenen Antikörperwerte wesentlich niedriger liegen als jene, die mit Rinderserumalbumin beschichteten Cellulosescheiben erhalten werden (Abb. 7). Daraus folgt, daß der Mikrotiterplatten-RIA insbesondere für diese Personengruppe wegen des deutlich geringeren störenden Einflusses von Cellulose-bindendem IgG besser geeignet ist als der übliche RIA mit Cellulosescheiben. Die klinische Relevanz der mit Cellulose reagierenden Immunglobuline ist bisher unklar.

\section{Methodenvergleich}

Vergleichsuntersuchungen zwischen PapierscheibenRIA und Mikrotiterplatten-RIA ergaben eine gute Korrelation bei Verwendung von Patientenseren ohne Cellulose-bindende IgG-Antikörper $(r=0,96)$ (siehe Abb. 8); demgegenüber ergibt sich für Patienten mit Cellulose-bindendem IgG erwartungsgemäß eine geringe bzw. fehlende Korrelation (nicht dargestellt).

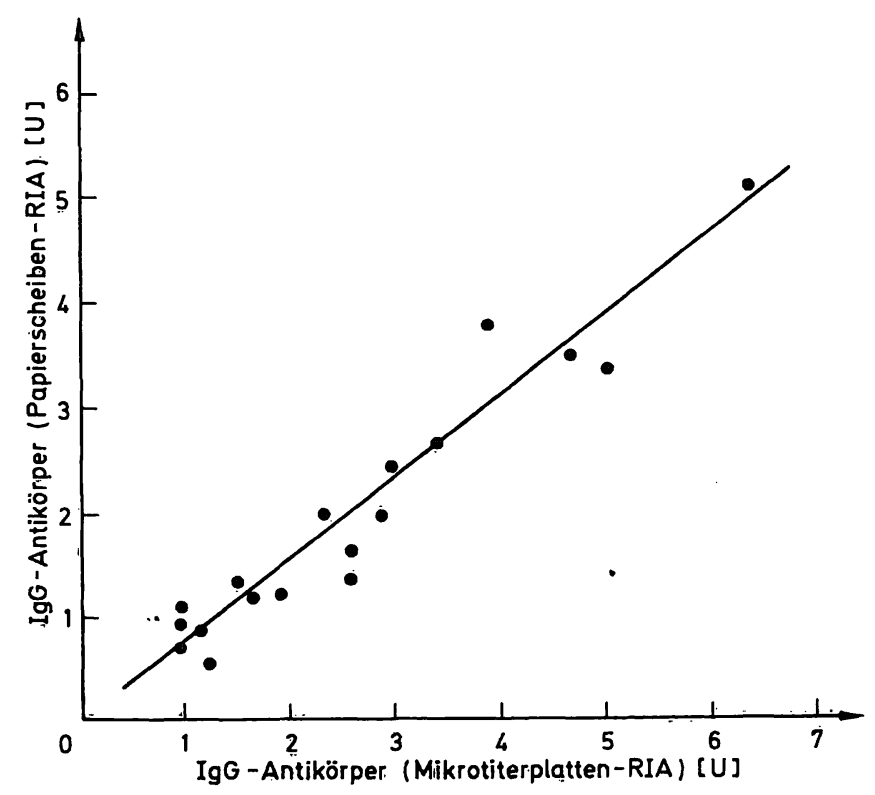

Abb. 8. Vergleichsuntersuchungen zwischen Papierscheibenund Mikrotiterplatten-RIA bei Patienten ohne Cellulose-bindende IgG-Antikörper:

Aspergillus fumigatus-Antigene; $\mathrm{n}=18 ; \mathrm{r}=0,96$; $y=0,75 x+0,01$

\section{Diskussion}

Ziel dieser Arbeit war es, einen möglichst empfindlichen und spezifischen Test für IgG-Antikörper gegen verschiedene, mit der Farmerlunge assoziierte mikrobielle Antigene zu entwickeln, welcher zudem auch für Seren mit Cellulose-bindenden Antikörpern geeignet sein sollte.

Um eine hohe Empfindlichkeit zu gewährleisten, d.h. um zu erreichen, daß sich möglichst viele antigenspezifische Antikörper binden, sollte in den Mikrotiterplatten ein Überschuß an Antigen vorliegen. Dieses Ziel ist bei Verwendung von nicht aktivierten Mikrotiterplatten nur schwer zu erreichen, da hier die Bindungskapazität der Plastikoberfläche relativ niedrig ist. Erhöht man durch Steigerung der Antigenkonzentration während des Beschichtungsvorgangs die Menge an adsorbiertem Antigen an der Mikrotiterplatte, so löst sich offensichtlich wegen nicht ausreichend fester Bindung während der Inkubation mit Serum ein Teil des Antigens von der Plastikoberfläche $a b$, und zwar um so mehr, je größer die ursprünglich absorbierte Menge war. Abgelöste Antigen-Moleküle treten in Konkurrenz mit gebundenem Antigen um die dagegen gerichteten Antikörper und reduzieren auf diese Weise die Anzahl der mit dem Antigen der Mikrotiterplatten reagierenden Antikörper (10). Das Resultat ist eine erhebliche Abhängigkeit des Testergebnisses von der verwendeten Antigenmenge, d. h. bei einer eng umschriebenen Antigenkonzentration liegt ein ausgeprägtes Optimum vor (Abb. $1 \mathrm{~d}$ ). Demgegenüber ist die Antigenbindungskapazität mit Glutaraldehyd aktivierter Mikrotiterplatten etwa $10 \mathrm{mal}$ größer als die von nicht aktivierten Mikrotiterplatten; außerdem sind die Antigene hier stärker an die Plastikoberfläche gebunden. Daraus resultieren zweierlei Vorteile: Zum einen kann man bei mit Glutaraldehyd aktivierten Mikrotiterplatten mit einem großen Antigenüberschuß arbeiten und dadurch die Empfindlichkeit des Assays steigern. Zum anderen ist es aufgrund des Plateaus der Antigenbindungskurve (Sättigungskurve, siehe Abb. 1c und Abb. 3) einfacher, mit in verschiedenen Versuchen beschichteten Mikrotiterplatten reproduzierbarere Ergebnisse zu erhalten als bei nicht aktivierten Mikrotiterplatten mit ihrem engen Optimum (siehe Abb. 1 d). Der genaue Wirkungsmechanismus der „Aktivierung“ von Polystyroloberflächen durch Behandlung mit Glutaraldehyd ist bisher ungeklärt.

Zur Frage der Anwendbarkeit des MikrotiterplattenRIA bei Seren mit Cellulose-bindenden Antikörpern läßt sich feststellen, daß dieser Test hierfür hervorragend geeignet und dem ansonsten bewährten Papierscheiben-RIA deutlich überlegen ist. 
Darüber hinaus kann der Mikrotiterplatten-RIA mit geringem Aufwand weitgehend automatisiert werden und bietet sich somit besonders für Screening-Untersuchungen an.

\section{Literatur}

1. Baur, X. (1986) Asthma, Alveolitis, Aspergillose. Springer Verlag, Heidelberg

2. Wide, L., Bennich, J. \& Johannsson, S. G. O. (1967) Lancet II, 1105.

3. Dewair, M. \& Baur, X. (1984) J. Immunol. Methods 75, 117-128.

4. Kronvall, G. \& Williams, R. C. (1969) J. Immunol. 103, 828.

5. Ouchterlony, O. (1962) Progr. Allergy 6, 30-154.

\section{Danksagung}

Unser Dank gilt Frau Barbara Jarosch füir die Durchführung eines Teils der radioimmunologischen Untersuchungen.

6. Vogelmeier, C., König, G., Baur, 'X., Dewair, M. \& Dexheimer, E. (1986) Atemw.-Lüngenkrkh. 12, $298-299$.

7. Dewair, M. \& Baur, X. (1987) Clin. Chim. Acta 163, 87 = 95.

8. Lowry, O. H., Rosebrough, N. J., Farr, A. L. \& Randall, R. J. (1951) J. Biol. Chem. 193, 265-275.

9. Baur, X., Fruhmann, G. \& Rienmüller, R. (1981) Prax. Pneumol. 35, 308-315.

10. Engvall, E. \& Perlmann, P. (1972) J. Immunol. 100, 129135.

Privat-Dozent Dr. X. Baur

Pneumologische Abteilung

Medizinische Klinik I

Klinikum Großhadern

Marchioninistr. 15

D-8000 München 70 